\title{
Multi Response Optimization of Simultaneous Fixation of Reactive Printing and Crease Resistant Finishing Using Desirability Function
}

\author{
Fareha Asim ${ }^{1, *}$, Muzzaffar Mahmood ${ }^{2}$ \\ ${ }^{1}$ Department of Textile Engineering, NED University of Engineering, Technology Karachi, Pakistan \\ ${ }^{2}$ Department of Mechanical Engineering, NED University of Engineering, Technology Karachi, Pakistan
}

\begin{abstract}
The single step fixation process for reactive printing and crease resistant finishing of cotton fabric with four potential factors namely; concentrations of dye and crease resistant, fixation method and temperature has been statistically analysed in this work. The optimum conditions of factors and levels of simultaneous fixation have been explored. A single step process for reactive printing and crease resistant finishing of cotton fabric is described. Evaluations of the process were made with respect to K/S, dry and wet crease recovery, tensile and tear strength, fastness to washing, light \& rubbing, resistance to abrasion and pilling. An Econtrol fixation at a temperature of $145^{\circ} \mathrm{C}$ was proved to be efficient for imparting single-step reactive print fixation and crease resistant finishing to cotton fabric.
\end{abstract}

Keywords Crease Resistance Finishing, Desirability Function,Econtrol, Optimization, Reactive Printing

\section{Introduction}

Modern textile processes have high demands concerning the combined application of crease resistance finishing and reactive printing. Various attempts have been made on simultaneous fixation of reactive dyeing and crease resistance finishing[1-4] but very few studies have been reported on combined application of reactive printing and creases resistance finishing[5-6]. Reports in literature revealed that a number of attempts was made for combined pigment printing and crease resistance finishing[7], due to the similar chemistry to cellulose cross linking agents and binders and the similar application conditions. However development and optimization of the process for reactive printing and crease resistance finishing is a novel approach. The concept of wet on wet fixation using an E Control process for the combined fixation of reactive printing and crease resistance finishing was investigated in this work.

The conventional optimization of the process parameters is costly in terms of time and material. Each process parameter has to be optimized one by one with several repetitions. The idea of this work is to use a model based approach due to the complexity of the chemical

* Corresponding author:

fareha@neduet.edu.pk (Fareha Asim)

Published online at http://journal.sapub.org/statistics

Copyright (C) 2012 Scientific \& Academic Publishing. All Rights Reserved and physical operational sequence with the combined fixation of reactive printing and crease resistance finishing process.

This paper uses desirability function to determine the optimum parameters of simultaneous fixation of reactive printing and crease resistance finishing for optimization of $\mathrm{K} / \mathrm{S}$, dry and wet crease recovery, tensile and tear strength, fastness to washing, light $\&$ rubbing, resistance to abrasion and pilling.

The $2^{1} \cdot 3^{3}$.mixed factorial design for the four controllable factors viz. chroma, concentration of crease resistant, fixation method and fixation temperature was used for this work to find the optimum conditions of factors and levels in simultaneous fixation. The multi response optimization was attempted through desirability function. These responses can be given equalwieghtage or the wieghtage of responses can be varied according toindustrial requirements. The optimization techniques like utility concept, principal component analysis etc.

\section{Desirability function}

A useful approach for optimization of multiple responses is to use the simultaneous optimization technique popularized by Derringer and Suich $[8,9]$. Their procedure makes use of desirability function. The general approach is to first convert each response yi into an individual desirability function di that varies over the range. 


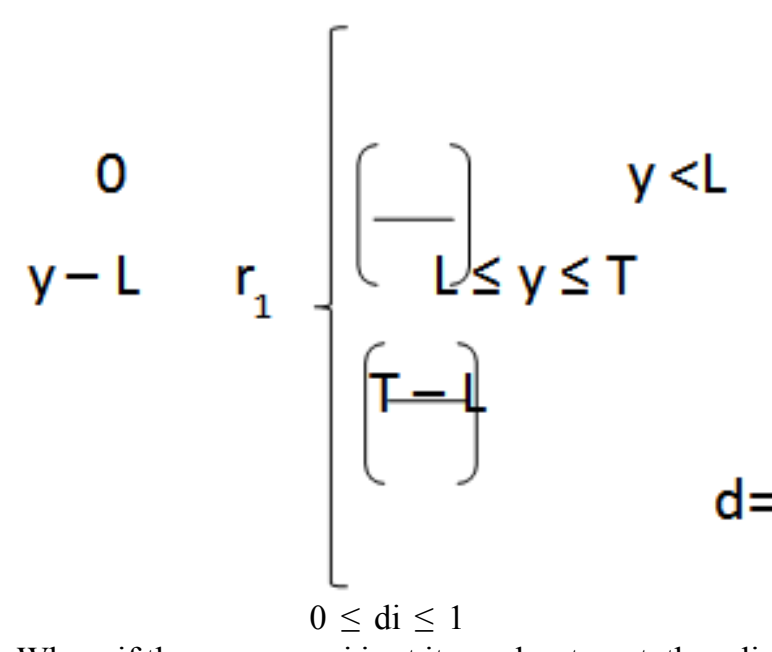

Where if the response yi is at its goal or target, then $\mathrm{di}=1$, and if the response is outside an acceptable region, $\mathrm{di}=0$. Then the design variables are chosen to maximize the overall desirability.

$$
\mathrm{D}=(\mathrm{d} 1 . \mathrm{d} 2 \ldots \ldots . \mathrm{dm}) 1 / \mathrm{m}
$$

Where there are $\mathrm{m}$ responses.

Table 1. Factors and respective levels used in $2^{1} \cdot 3^{3}$ mixed factorial design

\begin{tabular}{|lcccc|}
\hline & & \multicolumn{3}{c|}{} \\
\cline { 3 - 5 } & & -1 & 0 & +1 \\
\hline & Chroma & $1 \%$ & $2 \%$ & $\mathbf{3 \%}$ \\
\hline B & Conc. Of Crease Resistant & $100 \mathrm{~g} / 1$ & $150 \mathrm{~g} / 1$ & $\mathbf{2 0 0 g} / \mathbf{l}$ \\
\hline C & Fixation Method & Curing & E-Control \\
\hline D & Fixation Temperature & $\mathbf{1 3 0}^{\circ} \mathrm{C}$ & $\mathbf{1 4 0}^{\circ} \mathrm{C}$ & $\mathbf{1 5 0}^{\circ} \mathrm{C}$ \\
\hline
\end{tabular}

\section{Experimental}

\subsection{Material}

\subsubsection{Fabric}

Commercially Singed, desized, scoured, bleached and mercerized cotton fabric with satin weave structure, $40 \times 40 \mathrm{~s}$, 130 ends/inch x 73 picks/inch, and an area density of approximately $136 \mathrm{~g} / \mathrm{m} 2$ was used in this research work.

\subsubsection{Chemical and Colorants}

The Crease Recovery finishing agent used was Arkofix NEC (Clariant), based on modified N-methyloldihydroxy ethylene urea. Magnesium chloride $\left(\mathrm{MgCl}_{2}\right)$ was used to catalyze the CR finishing, Solusoft MW (Silicon softener), Ceranine-L (An ionic Softener) and Imercol PCLF (Wetting Agent).

The reactive dyes used were Drimarine Red P2B (Clariant), based on MCT reactive group. Other chemicals used in this research work were commercially available thickener Lamitex HP (sodium alginate), sodium bicarbonate, urea, Reduction Inhibitor (Revatol S) and sodium hexameta phosphate as a sequestrant.

\subsection{Methods}

\subsubsection{Print-finish Paste Manufacture}

A concentration of $2.50-3.00 \% \mathrm{w} / \mathrm{w}(30 \mathrm{~g} / \mathrm{kg})$ of thickener Lamitex HP (to maintain the $60-65 \mathrm{dPa}$ viscosity range recommended by the supplier) was added to produce stock paste, with continuous high speed stirring, to the required volume of water. This was followed by the gradual addition of Urea $200 \mathrm{~g} / \mathrm{kg}$, sodium bi carbonate $30 \mathrm{~g} / \mathrm{kg}$, Revatol S 10 $\mathrm{gm} / \mathrm{kg}$ and sodium hexa meta phosphate $5 \mathrm{gm} / \mathrm{kg}$ with continuous stirring giving a final stock paste viscosity of 60-65dPa.However urea is not added in the stock paste manufactured for the experiments conducted using E Control method for fixation. The printing pastes of different concentrations were prepared with Drimarine Red P2B as outlined in Table 1.During stock and print paste preparation a vigorous high speed stirring for $10 \mathrm{~min}$ was required to obtain a homogenous paste after adding all reagents. The viscosities of all types of pastes were measured using a Brookfield Viscometer, Type LV. The CR finishing liquor was prepared by using Magnesium Chloride $25 \%$ of CR but not greater than $30 \mathrm{~g} / \mathrm{l}$, Solusoft MW 20g/l, Ceranine-L 20g/1 and Imercol, PCLF $1 \mathrm{~g} / 1$. The final finish bath was prepared with Arkofix NEC as outlined in Table 1.

\subsubsection{Print-finish Procedure}

The combined process of reactive printing and CR finishing was carried out as follows: In the first stage the fabric was immersed in an aqueous solution of CR finish liquor, and then squeezed to obtain a $70 \%$ wet pickup. The wet fabric was then dried at $60^{\circ} \mathrm{C}$ for $7 \mathrm{~min}$. In the second stage the treated fabric was printed by the lab scale Rotary Printing machine (Zimmer).

The printed fabric going to be fixed though Curing process was again dried at $60^{\circ} \mathrm{C}$ for $7 \mathrm{~min}$. However, the printed fabric going to be fixed through E Control process was not dried. In the third stage, the print-finish fabric was fixed. The preparation of finish bath, printing recipe and fixation method and temperature were employed in accordance with the experimental design arrangement as stated in Table 1. The fixed samples were finally washed in $1 \mathrm{~g} / 1$ non-ionic detergent until all un reacted dyes and chemicals were removed from the fabric surface.

\subsubsection{Evaluation of Fabric Properties}

The easy-care properties imparted by the CR finish were evaluated by measuring the dry crease recovery angles (DCRA) using AATCC-66. The fabric strength properties were assessed by measuring the breaking load of fabric using the standard test procedure ASTM D 5035. The tear strength of fabric was evaluated using ASTM D1424. The standard test procedures adopted for color fastness properties included: 
(a) color staining to rubbing, AATCC-08; (b) the loss of color and staining to washing, ISO $\mathrm{C} 2 \mathrm{~S}$; and (c) color fastness to light, ISO 105-B02. Each value reported for DCRA and breaking load is the mean of two samples tested, each having a coefficient of variance not more than +/$5 \%$.The fabric pilling and abrasion resistance was examined using ISO -12945-2 (100 cycles) and ISO 12947) @ 2500 rubs respectively. Shade depth values were assessed spectrophotometrically and expressed in terms of the Kubelka-Munk (K/S) relationship. The samples processed with simultaneous fixation were compared with those produced from a standard two-step process of printing and finishing.

\subsection{Experiment Design}

$2^{1} \cdot 3^{3}$. mixed full factorial design was used to explore the effect of different factors namely: (i) chroma, (ii) concentration of crease resistant, (iii) fixation method and (iv) fixation temperature on combined reactive printing and crease resistance finishing. A $2^{1} .3^{3}$ mixed factorial design with two replicates was run according to the design matrix as shown in Table 1. The experiments were performed in random order. The results were analyzed and optimized using software Design Expert 8.0. The responses investigated were the $\mathrm{K} / \mathrm{S}$, dry and wet crease recovery, tensile and tear strength, fastness to washing, light \& rubbing, resistance to abrasion and pilling.

\section{Multi-response Optimization Using Desirability Function}

To overcome the problem of conflicting responses of single response optimization, multi-response optimization was used. In multi response optimization, desired wieghtage is given to all responses (equal wieghtage in the present study) and for a combined influence of all responses desirability is determined for varying values of input parameters. Table 2 shows the range of input parameters and that of responses and the goal and weights assigned to each parameter. The target values assigned were obtained from the experiments performed for the standard two-step process of reactive printing and CR finishing (shade depth $2 \%$ and concentration of CR 100g/l) as shown in Table 3.

Table 2. Range of input parameters and responses

\begin{tabular}{|c|c|c|c|c|c|c|}
\hline Constraints Name & Goal & Lower limit & Upper limit & $\begin{array}{l}\text { Lower } \\
\text { weight }\end{array}$ & $\begin{array}{c}\text { Upper } \\
\text { weight }\end{array}$ & Importance \\
\hline Chroma (\%) & is in range & 1 & 3 & 1 & 1 & 3 \\
\hline Conc. Of CR (g/l) & is in range & 100 & 200 & 1 & 1 & 3 \\
\hline Fixation Mode & is in range & Curing & Econtrol & 1 & 1 & 3 \\
\hline Fixation Temp $\left({ }^{\circ} \mathrm{C}\right)$ & is in range & 130 & 150 & 1 & 1 & 3 \\
\hline $\mathrm{K} / \mathrm{S}$ & is target $=10.1$ & 9 & 10.2 & 1 & 1 & 5 \\
\hline DCRA Warp $\left(^{\circ}\right)$ & is target $=110$ & 110 & 140 & 1 & 1 & 5 \\
\hline DCRA Weft $\left({ }^{\circ}\right)$ & is target $=120$ & 115 & 168 & 1 & 1 & 5 \\
\hline Tensile Strength Warp (N) & minimize & 310 & 530.7 & 1 & 1 & 3 \\
\hline Tensile Strength Weft (N) & minimize & 125 & 246 & 1 & 1 & 3 \\
\hline Tear Strength Warp (N) & minimize & 14.84 & 34.35 & 1 & 1 & 3 \\
\hline Tear Strength Weft (N) & minimize & 11 & 23.79 & 1 & 1 & 3 \\
\hline Pilling & is in range & 3 & 4 & 1 & 1 & 3 \\
\hline Wash Fastness & is in range & 4 & 5 & 1 & 1 & 3 \\
\hline Rubbing Dry & maximize & 4 & 5 & 1 & 1 & 3 \\
\hline Rubbing Wet & maximize & 4 & 5 & 1 & 1 & 3 \\
\hline Light Fastness & is in range & 3 & 4 & 1 & 1 & 3 \\
\hline Abrasion Resistance & is in range & 3 & 4 & 1 & 1 & 3 \\
\hline
\end{tabular}


Table 3.Optimum parameters for Standard Two-step Process of Reactive printing and CR Finishing

\begin{tabular}{|c|c|c|c|c|c|c|c|c|c|c|c|c|}
\hline $\mathrm{K} / \mathrm{S}$ & $\begin{array}{l}\text { DCRA } \\
\text { Warp } \\
(\quad \square)\end{array}$ & $\begin{array}{l}\text { DCRA } \\
\text { Weft } \\
(\quad \square)\end{array}$ & $\begin{array}{l}\text { Tensile } \\
\text { Strength } \\
\text { Warp } \\
\text { (N) }\end{array}$ & $\begin{array}{c}\text { Tensile } \\
\text { Strength } \\
\text { Weft } \\
\text { (N) }\end{array}$ & $\begin{array}{c}\text { Tear } \\
\text { Strength } \\
\text { Warp } \\
\text { (N) }\end{array}$ & $\begin{array}{c}\text { Tear } \\
\text { Strength } \\
\text { Weft } \\
\text { (N) }\end{array}$ & Pilling & $\begin{array}{l}\text { Wash } \\
\text { Fastness }\end{array}$ & $\begin{array}{c}\text { Dry } \\
\text { Rubbing }\end{array}$ & $\begin{array}{c}\text { Wet } \\
\text { Rubbing }\end{array}$ & $\begin{array}{l}\text { Light } \\
\text { Fastness }\end{array}$ & $\begin{array}{c}\text { Abrasion } \\
\text { Resistance }\end{array}$ \\
\hline 10.1 & 110 & 120 & 315 & 125 & 10.995 & 9.01 & $3-4$ & $4-5$ & $4-5$ & $4-5$ & $3-4$ & 3-4 \\
\hline
\end{tabular}

Table 4. Input Parameters for high value of desirability

\begin{tabular}{|c|c|c|c|c|c|c|c|c|c|c|c|c|c|c|c|c|c|c|}
\hline $\begin{array}{l}\text { S. } \\
\text { No } \\
\text {. }\end{array}$ & $\begin{array}{c}\text { Chroma } \\
(\%)\end{array}$ & $\begin{array}{l}\text { Conc. of } \\
\text { CR (g/l) }\end{array}$ & $\begin{array}{c}\text { Fixation } \\
\text { Mode }\end{array}$ & $\begin{array}{c}\text { Fixation } \\
\text { Temp } \\
\left({ }^{\circ} \mathrm{c}\right)\end{array}$ & $\mathrm{K} / \mathrm{S}$ & $\begin{array}{c}\text { DCRA } \\
\operatorname{Warp}\left(^{\circ}\right)\end{array}$ & $\begin{array}{c}\text { DCRA } \\
\text { Weft }\left(^{\circ}\right)\end{array}$ & $\begin{array}{c}\text { Tensile } \\
\text { Strength } \\
\text { Warp (N) }\end{array}$ & $\begin{array}{c}\text { Tensile } \\
\text { Strength } \\
\text { Weft }(\mathrm{N})\end{array}$ & $\begin{array}{c}\text { Tear } \\
\text { Strength } \\
\text { Warp (N) }\end{array}$ & $\begin{array}{c}\text { Tear } \\
\text { Strength } \\
\text { Weft (N) }\end{array}$ & $\begin{array}{l}\text { Pillin } \\
\text { g }\end{array}$ & $\begin{array}{l}\text { Wash } \\
\text { fastn } \\
\text { ess }\end{array}$ & $\begin{array}{l}\text { Dry } \\
\text { Rub }\end{array}$ & $\begin{array}{l}\text { Wet } \\
\text { Rub }\end{array}$ & $\begin{array}{l}\text { Light } \\
\text { Fastness }\end{array}$ & $\begin{array}{c}\text { Abra } \\
\text { sion } \\
\text { Resis } \\
\text { tance }\end{array}$ & $\begin{array}{l}\text { Desira } \\
\text { bility }\end{array}$ \\
\hline 1 & 3 & 131.8 & Econtrol & 146.7 & 9.6 & 125.6 & 124.8 & 415.8 & 201.9 & 28.4 & 19.2 & 4 & 4.4 & 4.9 & 4 & 4 & 4.0 & 0.81 \\
\hline 2 & 3 & 132.9 & Econtrol & 146.7 & 9.5 & 125.7 & 125.4 & 416.5 & 202.2 & 28.3 & 19.2 & 4 & 4.4 & 4.9 & 3.7 & 4.2 & 4.0 & 0.79 \\
\hline 3 & 3 & 132.6 & Econtrol & 146.7 & 9.5 & 125.6 & 125.2 & 416.3 & 202.2 & 28.4 & 19.2 & 4 & 4.4 & 4.9 & 3.7 & 4.2 & 4.0 & 0.79 \\
\hline 4 & 3 & 131.3 & Econtrol & 146.7 & 9.6 & 125.6 & 124.5 & 415.6 & 201.8 & 28.5 & 19.2 & 3.9 & 4.4 & 4.9 & 3.7 & 4.2 & 4.0 & 0.71 \\
\hline 5 & 2.97 & 127.4 & Econtrol & 146.5 & 9.6 & 125.3 & 123.0 & 415.4 & 201.2 & 28.8 & 19.0 & 4 & 4.4 & 4.9 & 3.7 & 4.1 & 4.0 & 0.69 \\
\hline 6 & 2.95 & 129.1 & Econtrol & 146.5 & 9.5 & 125.3 & 124.0 & 417.9 & 201.9 & 28.8 & 18.9 & 4 & 4.4 & 4.9 & 3.7 & 4.0 & 4.0 & 0.68 \\
\hline 7 & 3 & 117.8 & Econtrol & 147.4 & 9.7 & 124.7 & 118.6 & 415.9 & 193.8 & 29.1 & 18.9 & 3.6 & 4.3 & 4.9 & 3.8 & 4.0 & 4.1 & 0.66 \\
\hline
\end{tabular}



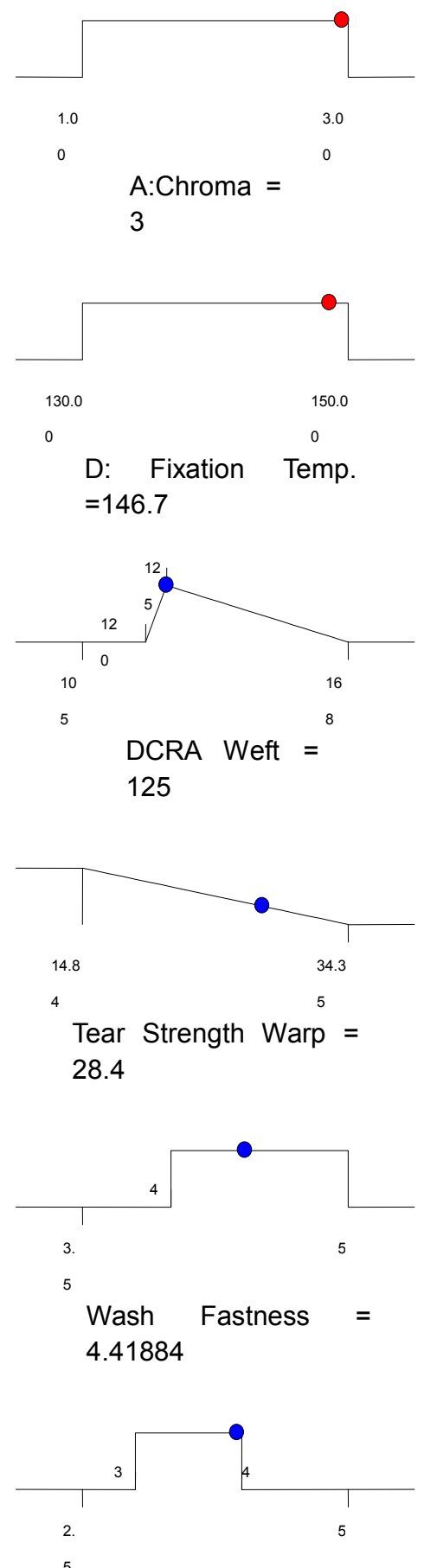

Light Fastness $=$

4
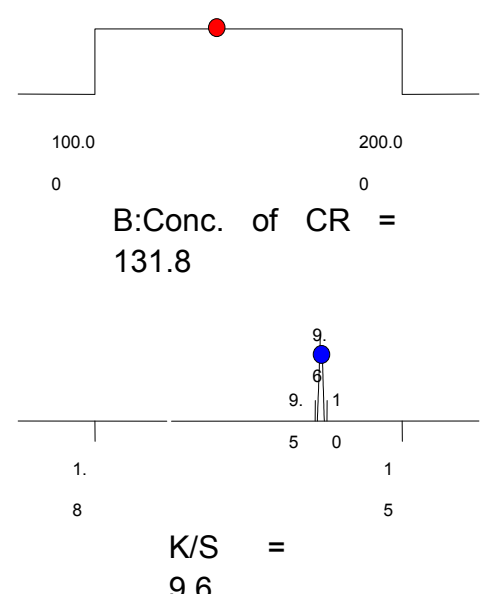

9.6
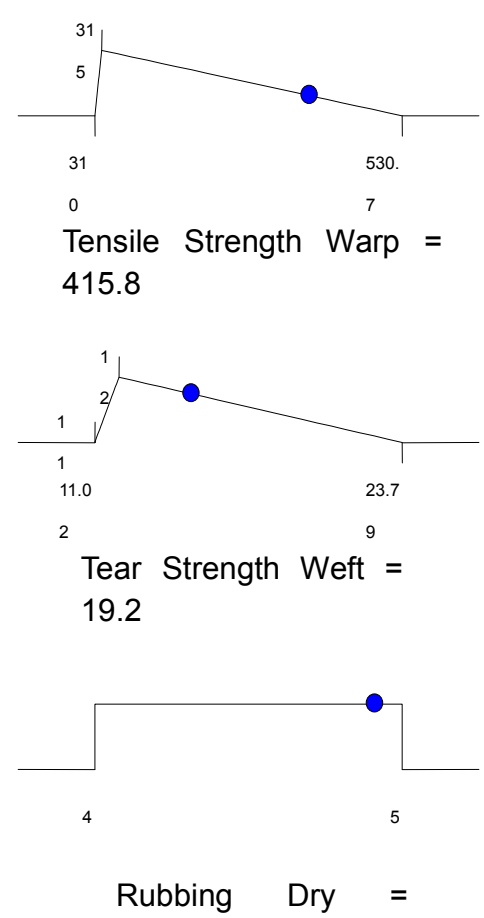

4.91278
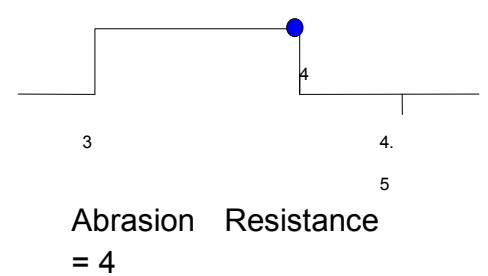

Figure 1. Ramos for various factors
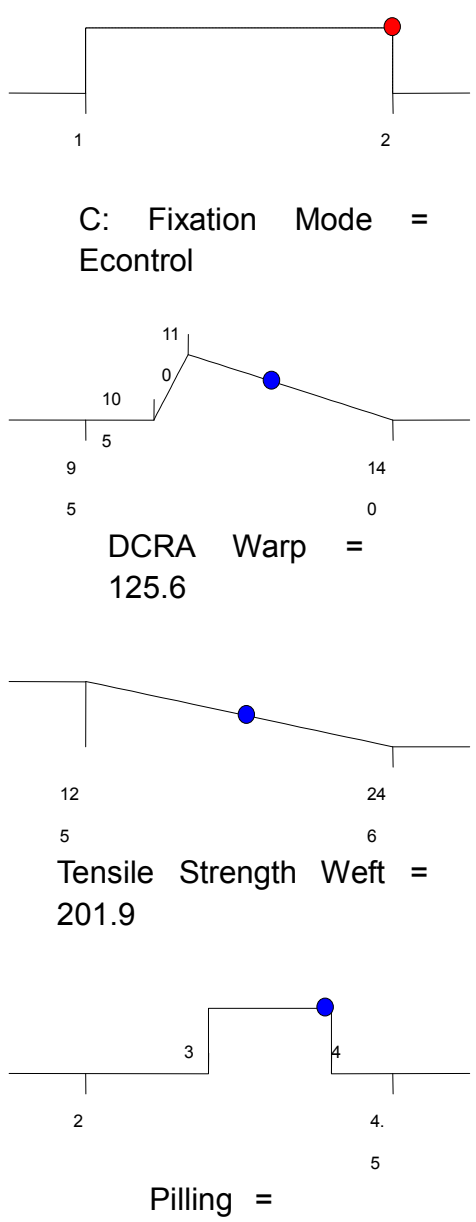

4

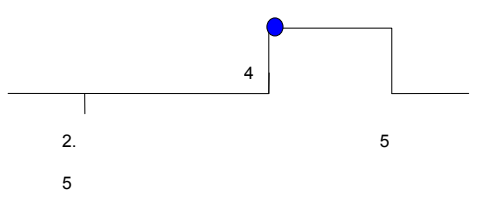

Rubbing Wet $=$

4

Desirability =

0.81
Figure 1 shows the ramps of various factors (all the four responses are given equal weightage). Table 4 revealed that the overall desirability values are highin the region of Econtrolmode of fixation. This is owing to the fact that wet on wet fixation of Econtrol process is based on the temperature of the fabric reached during the fixation process, which depends on the relative humidity inside the hot air/controlled moisture fixation chamber
The adequate parameters to maximize the overall desirability involve the following specifications:

-Chroma $=3 \%$

-Concentration of CR = $131 \mathrm{~g} / 1$

-Fixation Mode = E Control

-Fixation Temperature $=145^{\circ} \mathrm{C}$

The following step consists of setting the optimal input variable levels that have maximized the overall desirabilities. 
That is, the optimum parameters would be set as mentioned in Table 2. In this case the single step process of fixation of reactive dye and $\mathrm{CR}$ finishing showed similar results as a two-step process. Moreover the wet on wet fixation of the Econtrol process gives notably high values of tensile and tear strengths both in warp and weft directions as shown in Table 4. In contrast, the specifications of K/S, DCRA warp and weft, pilling \& abrasion resistance, wash, rub and light fastness are barely satisfied. However, the amount of dye and $\mathrm{CR}$ used in the simultaneous fixation will be slightly higher as compared to conventional process of fixation for achieving the same depth of shade and DCRA. Furthermore, it is unnecessary to use urea to print cotton in the CPF process using wet on wet fixation by the Econtrol process.

\section{Conclusions}

This paper optimizes process parameters for simultaneous fixation of reactive printing and crease resistant finish fabric using multi response optimization. To overcome the problem of conflicting responses of single response optimization, multi-response optimization was used. In multi response optimization, equal weightage is given to all responses and for a combined influence of all responses desirability is determined for varying values of input parameters. The target values assigned were obtained from the experiments performed for the conventional two-step process of reactive printing and CR finishing. The optimal value with specified desirability was calculated using the Design Expert software.

Table 4 lists seven different desirable ranges of input parameters and responses which give overall high value of desirability. As clear from the Table 4, E control process at $145^{\circ} \mathrm{C}$ is enviable for getting high values of desirability and consequently a good substitute of the two-step process. Therefore, the fixation by the Econtrol process at $145^{\circ} \mathrm{C}$ for 5 minutes using the pad-dry-print-fix-wash method is desirable for getting high values of desirability and consequently a good substitute for the two-step process.

Furthermore in this model we can vary the objectives, the tolerance intervals and the corresponding weights of the responses as required by the customer.

\section{ACKNOWLEDGEMENTS}

The authors acknowledge the permission given by Clariant Pakistan Ltd, for carrying out the necessary experimental work.

\section{REFERENCES}

[1] Yongchun Dong, Jijun Wang and Pengfei Liu; Dyeing and Finishing of Cotton fabric in asingle bath with reactive dyes and citric acid, Coloration Technology, (2001) 262-265

[2] ArijitChakarborty and ChakradharCutta; Kinematics of concurrent Dyeing and Finishing- a Critical Study, ENVIROENERGY (2009) 701-711

[3] Christian Schramm, Sandra BischofVukusic and DragoKatovic; Non-formaldehyde durable press finishing of dyed fabrics: evaluation of cotton-bound polycarboxylic acids, Coloration Technology (2002) 244-249

[4] Y.Kawahara, M. Shioya, A. Takavu; Effect of nunformaldehyde finishing process on dyeing and mechanical properties of cotton fabrics, American dyestuff Reporter (1996) 88-91

[5] FarehaAsim and MuzzaffarMahmood; Combined process for reactive printing and crease resistance finishing for cotton fabric using an experimental design technique, Pakistan Textile Journal (2010) 52-56

[6] S.M. Mortazavi, M.A. Alsharif, M.Jannesari; A study on simultaneous fixation of reactive dye printing and crease resist finishing on cotton fabric (Effect of DMDHEU concentration, types of catalyst and drying conditions), http://140.134.132.124:8080/dspace/bitstream/2377/3912/1/c e05atc902007000039.pdf accessed 12 March 2010

[7] FaheemUddin and Mike Lomas; Combined crease recovery finishing and pigment printing Coloration Technology, (2005) $158-163$

[8] Derringer I.G., R. Suich; Simultaneous optimization of several response variables, Journal of Quality Technology, 12(1980) 214-219

[9] Douglas C. Montgomery; Design and Analysis of Experiments, John Wiley \& Sons, Sixth Edition 423-427

[10] Franz Peter Tolksdorf; The modern art of continuous dyeing, Journal for Asia on Textile \& Apparel (2006) 